\title{
A bacterial hemerythrin-like protein MsmHr inhibits the SigF-dependent hydrogen peroxide response in mycobacteria
}

\author{
Xiaojing $\mathrm{Li}^{1+}$, Jun $\mathrm{Tao}^{1+}$, Xinling $\mathrm{Hu}^{1+}$, John Chan ${ }^{2}$, Jing Xiao ${ }^{1}$ and Kaixia Mi ${ }^{1,3 *}$ \\ ${ }^{1}$ CAS Key Laboratory of Pathogenic Microbiology and Immunology, Institute of Microbiology, Chinese Academy of Sciences, Beijing, China \\ ${ }^{2}$ Departments of Medicine and Microbiology and Immunology, Albert Einstein College of Medicine, Bronx, NY, USA \\ ${ }^{3}$ Beijing Key Laboratory of Microbial Drug Resistance and Resistome, Beijing, China
}

\author{
Edited by: \\ Biswarup Mukhopadhyay, Virginia \\ Tech, USA \\ Reviewed by: \\ C. Martin Lawrence, Montana State \\ University, USA \\ James Moir, University of York, UK \\ Leif Kirsebom, Uppsala University, \\ Sweden \\ *Correspondence: \\ Kaixia Mi, Institute of Microbiology, \\ NO. 1 Beichen West Road, \\ Chaoyang District, Beijing 100101, \\ China \\ e-mail:mik@im.ac.cn \\ ${ }^{\dagger}$ These authors have contributed \\ equally to this work.
}

Hydrogen peroxide $\left(\mathrm{H}_{2} \mathrm{O}_{2}\right)$ is one of a variety of reactive oxygen species (ROS) produced by aerobic organisms. Host production of toxic $\mathrm{H}_{2} \mathrm{O}_{2}$ in response to pathogen infection is an important classical innate defense mechanism against invading microbes. Understanding the mechanisms by which pathogens, in response to oxidative stress, mediate defense against toxic ROS, can reveal anti-microbial targets and shed light on pathogenic mechanisms. In this study, we provide evidence that a Mycobacterium smegmatis hemerythrin-like protein MSMEG_2415, designated MsmHr, is a $\mathrm{H}_{2} \mathrm{O}_{2}$-modulated repressor of the SigF-mediated response to $\mathrm{H}_{2} \mathrm{O}_{2}$. Circular dichroism and spectrophotometric analysis of $\mathrm{MsmHr}$ revealed properties characteristic of a typical hemerythrin-like protein. An $m s m H r$ knockout strain of $M$. smegmatis $m^{2} 155(\Delta m s m H r)$ was more resistant to $\mathrm{H}_{2} \mathrm{O}_{2}$ than its parental strain, and overexpression of $\mathrm{MsmHr}$ increased mycobacterial susceptibility to $\mathrm{H}_{2} \mathrm{O}_{2}$. Mutagenesis studies revealed that the hemerythrin domain of $\mathrm{MsmHr}$ is required for the regulation of the $\mathrm{H}_{2} \mathrm{O}_{2}$ response observed in the overexpression study. We show that $\mathrm{MsmHr}$ inhibits the expression of SigF (MSMEG_1804), an alternative sigma factor that plays an important role in bacterial oxidative stress responses, including those elicited by $\mathrm{H}_{2} \mathrm{O}_{2}$, thus providing a mechanistic link between $\Delta m s m H r$ and its enhanced resistance to $\mathrm{H}_{2} \mathrm{O}_{2}$. Together, these results strongly suggest that $\mathrm{MsmHr}$ is involved in the response of mycobacteria to $\mathrm{H}_{2} \mathrm{O}_{2}$ by negatively regulating a sigma factor, a function not previously described for hemerythrins.

Keywords: mycobacteria, hemerythrin-like protein, MsmHr, SigF, hydrogen peroxide

\section{INTRODUCTION}

Hydrogen peroxide $\left(\mathrm{H}_{2} \mathrm{O}_{2}\right)$ is a universal oxidative stress molecule produced by aerobic organisms from all three domains of life (Imlay, 2008). The production of $\mathrm{H}_{2} \mathrm{O}_{2}$ by the host in response to pathogen infection is also an important innate defense mechanism (Fang, 2004). This ROS can be damaging via direct toxic effects or disruption of redox balance, the latter being critical for metabolic homeostasis and hence survival. An important intracellular pathogen, Mycobacterium tuberculosis has evolved many strategies to detoxify $\mathrm{H}_{2} \mathrm{O}_{2}$, some of which are unique to mycobacteria (Kumar et al., 2011; Trivedi et al., 2012). For example, M. tuberculosis, which lacks the conventional redox buffer glutathione, uses mycothiol (MSH), a lowmolecular-weight thiol that exists in millimolar quantities in the cytoplasm, to generate a reducing environment (Farhana et al., 2010); and MSH-deficient mycobacterial mutants are hypersusceptible to $\mathrm{H}_{2} \mathrm{O}_{2}$ (Rawat et al., 2002). The precise mechanisms by which MSH protects against oxidative stress and redox imbalance remain to be determined. M. tuberculosis also lacks classic sensors such as OxyR and SoxR for the detection of redox signals
(Imlay, 2013). The tubercle bacillus, however, expresses DosS and DosT (Kumar et al., 2007), two sensor histidine kinases whose heme iron plays a critical role in their response to the levels of $\mathrm{O}_{2}$, nitric oxide $(\mathrm{NO})$ and carbon monoxide $(\mathrm{CO})$. Interaction with these various gasses activates the kinase activity of DosS and DosT, relaying the signals to the response regulator DosR. WhiB3 is an Fe-S cluster transcription factor that controls the expression of the hypoxia regulon of M. tuberculosis (Bhat et al., 2012). Indeed, accumulating evidence suggests that the $M$. tuberculosis WhiB family of Fe-S cluster proteins plays important roles in regulating a wide spectrum of microbial functions including responses to oxidative stress and virulence (Burian et al., 2012; Saini et al., 2012a). Together, the DosS-DosT/WhiB3 paradigm underscores the importance of iron-containing proteins in the response of $M$. tuberculosis to redox signals, including those imposed by reactive oxygen intermediates.

The non-heme, di-iron, $\mathrm{O}_{2}$-binding hemerythrin-like proteins are present in all domains of life (Bailly et al., 2008; French et al., 2008). Bioinformatics analyses have revealed over 400 hemerythrin-like proteins in available prokaryotic genomes 
(Bailly et al., 2008; French et al., 2008). These proteins harbor the conserved hemerythrin domain either singly or jointly with another distinct functional domain (Bailly et al., 2008; French et al., 2008). Experimental evidence suggests that they can function as oxygen sensors and reserves, as well as mediate the delivery and transport of this diatomic gas (French et al., 2008). Dcr (Desulfovibrio chemoreceptor) H was the first bacterial hemerythrin-like protein to be identified. It has been proposed that the C-terminal hemerythrin domain of $\mathrm{DcrH}$, a member of the Dcr family of putative methyl-accepting chemotaxis proteins of the anaerobic sulfate-reducing bacterium Desulfovibrio vulgaris, functions to sense $\mathrm{O}_{2}$ (Xiong et al., 2000); the signal thus generated is proposed to be transduced to the transmitting domains to mediate chemotaxis (Xiong et al., 2000). The first single-domain hemerythrin-like protein was identified in Methylococcus capsulatus. The expression of the M. capsulatus hemerythrin-like protein is enhanced significantly with increasing concentrations of copper, and is thought to be an oxygen carrier that supplies copper-containing methane monooxygenase with oxygen (Kao et al., 2004; Karlsen et al., 2005; Chen et al., 2012). Despite the wide distribution of hemerythrin-like proteins in a wide variety of bacterial species, including $M$. tuberculosis (Xiong et al., 2000; Karlsen et al., 2005; Isaza et al., 2006; Justino et al., 2007; Onoda et al., 2011; Schaller et al., 2012), functional characterization studies are scarce.

Transcriptional regulation is critical to bacterial survival in response to various stresses. Sigma factors are the primary transcriptional regulators of bacterial gene expression. M. tuberculosis has 13 sigma factors, and SigH, SigE, SigL, and SigF play important roles in ROS detoxification (Rodrigue et al., 2006). SigF, a highly conserved sigma factor in the genus Mycobacterium (Rodrigue et al., 2006), is highly induced by various environmental stresses and during stationary phase (Demaio et al., 1996). In M. smegmatis, sigF deletion also increases susceptibility to oxidative stress (Gebhard et al., 2008; Humpel et al., 2010). Recently, a genome-wide gene expression study (Humpel et al., 2010) and work from our laboratory (Wu et al., 2012) have provided evidence that SigF regulates the expression of oxidative stress defense genes such as katA, $d p s 1$, and $\operatorname{sod} A$, but not kat $G$ and $a h p C$, genes that have been linked to mycobacterial resistance to isoniazid (Silva et al., 2003). These studies suggest that SigF-mediated resistance to $\mathrm{H}_{2} \mathrm{O}_{2}$ is independent of KatG and AhpC. This notion is also supported by the fact that SigF-deficient mutants do not display decreased susceptibility to isoniazid (Demaio et al., 1996; Humpel et al., 2010). Regulation of SigF in mycobacteria is generally thought to be predominantly at the post-transcriptional level via the action of anti-sigma and anti-anti-sigma factors (Michele et al., 1999; Beaucher et al., 2002; Singh and Singh, 2008). SigF is transcribed from two promoters, $\mathrm{P}_{\text {msmeg_1802 }}$ and $\mathrm{P}_{r b s w}$ (Gebhard et al., 2008), and transcriptional reporter fusion studies have shown that promoter $\mathrm{P}_{\text {msmeg_1802 }}$ responds to entry into the stationary phase and promoter $\mathrm{P}_{r b s w}$ is inducible upon treatment with D-cycloserine (Gebhard et al., 2008).

In this study, to investigate the role of hemorythrin-like proteins in mycobacteria, we cloned, expressed, and characterized the M. smegmatis $\mathrm{mc}^{2} 155$ strain $\mathrm{MsmHr}$ protein (encoded by msmeg2415). Using a genetic and biochemical approach, we show that (i) MsmHr displays circular dichroism (CD) and UVvis spectrophotometric features typical of a hemerythrin-like protein; (ii) relative to wild-type bacilli, the $m s m H r$ knockout strain $(\Delta m s m H r)$ is more resistant to $\mathrm{H}_{2} \mathrm{O}_{2}$ and $\mathrm{mc}^{2} 155$ overexpressing $\mathrm{MsmHr}$ exhibits enhanced $\mathrm{H}_{2} \mathrm{O}_{2}$ susceptibility; (iii) the $\mathrm{H}_{2} \mathrm{O}_{2}$ response is dependent on the hemerythrin domain; (iv) $\mathrm{MsmHr}$ represses $s i g F$ transcription through the promoter $\mathrm{P}_{r b s w}$, and thus participates in regulating the SigF-mediated $\mathrm{H}_{2} \mathrm{O}_{2}$ response. Our results indicate that $\mathrm{MsmHr}$, the first mycobacterial hemorhythrin-like protein to be characterized, is involved in the $\mathrm{H}_{2} \mathrm{O}_{2}$ response in mycobacteria and provide insight into its mechanism.

\section{MATERIALS AND METHODS CULTURE MEDIUM AND GROWTH CONDITIONS}

M. smegmatis cultures were grown in Middlebrook 7H9 medium (Becton Dickinson, Sparks, MD) supplemented with ADS enrichment (Albumin-Dextrose Saline containing 5\% (w/v) Bovine serum albumin fraction V, 2\% (w/v) D-Dextrose and 8.1\% (w/v) $\mathrm{NaCl}$ ) (Jacobs et al., 1991), 0.05\% (v/v) Tween 80, and $0.5 \%$ (v/v) glycerol (Beijing Modern Eastern Finechemical Co. Ltd, Beijing). Middlebrook 7H10 medium supplemented with ADS enrichment and $0.5 \%(\mathrm{v} / \mathrm{v})$ glycerol was used as the solid medium for examination of growth status. Growth was also examined in minimal Sauton's medium ( $4 \mathrm{~g}$ asparagine, $2 \mathrm{~g}$ sodium citrate, $0.5 \mathrm{~g} \mathrm{~K}_{2} \mathrm{HPO}_{4} \cdot 3 \mathrm{H}_{2} \mathrm{O}, 0.5 \mathrm{~g} \mathrm{MgSO}_{4} \cdot 7 \mathrm{H}_{2} \mathrm{O}, 0.05 \mathrm{~g}$ ferric ammonium citrate, $60 \mathrm{~g}$ glycerol in $1 \mathrm{~L}$ of $\mathrm{H}_{2} \mathrm{O}$ supplemented with $0.05 \%(\mathrm{v} / \mathrm{v})$ Tween 80$)$ supplemented with antibiotics as indicated. Hygromycin (75 mg/L for M. smegmatis, $150 \mathrm{mg} / \mathrm{L}$ for Escherichia coli; Roche) and kanamycin $(25 \mathrm{mg} / \mathrm{L}$ for $M$. smegmatis, $50 \mathrm{mg} / \mathrm{L}$ for Escherichia coli; Amresco) were added to the medium as needed. All bacterial strains used in this study are listed in Table S1.

\section{GENERATION OF KNOCKOUT MUTANT STRAINS, COMPLEMENTATION STRAINS AND OVEREXPRESSION STRAINS}

The msmHr (msmeg_2415) and sigF (msmg_1804) deletion mutants were generated via a specialized transducing phage delivery system as previously described (Bardarov et al., 2002). The $5^{\prime}$-flanking region of $m s m H r$ was amplified by polymerase chain reaction (PCR) with the 2415LL/2415LR primer pair and the $3^{\prime}$-flanking region of $m s m H r$ was amplified with the 2415RL/2415RR primer pair (all primers are listed in Supplemental Table S2. The flanking regions of sigF were generated by amplifying the upstream and downstream regions of sigF using the 1804LL/1804LR and 1804RL/1804RR primer pairs, respectively. Amplified fragments were ligated with plasmid p0004S, digested with PflMI ( $m s m H r$ ) or AlwnI (sigF), and allelicexchange plasmids thus constructed were digested with PacI, and then ligated with PacI-digested phAE159. Phage packaging was performed using a MaxPlax packaging extract (Epicenter Biotechnologies, USA) to yield the knockout phages for $m s m H r$ (phAE-msmHr) and sigF (phAE-sigF). Specialized transduction was carried out as described previously (Bardarov et al., 2002). The knockout clones were screened by PCR using the primer pairs 2415InL/2415InR, 2415LLL/IL(R) and IR(F)/2415RRR for $m s m H r$ and 1804InL/1804InR, 1804LLL/IL(R), and 
IR(F)/1804RRR for sigF. Primer positions with respect to the appropriate genes are shown in Figure 2A and Figure S1. No $m s m H r$ or sigF mRNA was detected in the corresponding deletion strains by qRT-PCR using the appropriate primer pairs (Figure 2A and Figure S1). Complementation strains were constructed as described previously (Stover et al., 1991). Briefly, the full-length sequence of $m s m H r$ or sigF amplified from M. smegmatis genomic DNA was cloned into the integrating vector pMV361 (Stover et al., 1991) and the resultant plasmids were electroporated into the corresponding knockout strains to yield C- $\Delta m s m H r\left(\Delta m s m H r:: \mathrm{P}_{h s p 60}-m s m H r\right)$ and $\mathrm{C}-\Delta s i g F$ $\left(\Delta s i g F:: \mathrm{P}_{h s p 60}-s i g F\right)$. To over-express $m s m H r$, the $m s m H r$ fragment was subcloned into pMV261 (Stover et al., 1991) to yield pMV261-msmHr for transformation into M. smegmatis (O-msmHr).

\section{DETERMINATION OF SURVIVAL PHENOTYPES UNDER STRESS}

Early phase cultures $\left(\mathrm{OD}_{600}=0.3\right)$ of all tested strains were serially diluted (1:10) and spotted $(3 \mu \mathrm{l})$ onto solid 7H10 medium supplemented with ADS enrichment and stress-inducing chemical agents $\left(20 \mu \mathrm{M}\right.$ streptonigrin, $\left.250 \mu \mathrm{M} \mathrm{NaNO}_{2}\right)$ or subjected to low-pH stress (7H9 supplemented with ADS enrichment and $0.05 \%$ Tween 80 , pH 5.5). For peroxide stress, early-phase cultures were treated with $5 \mathrm{mM} \mathrm{H}_{2} \mathrm{O}_{2}$ for $3 \mathrm{~h}$, serially diluted (1:10) and spotted $(3 \mu \mathrm{l})$ onto solid $7 \mathrm{H} 10$ medium supplemented with $10 \%$ ADS. The optical density at $600 \mathrm{~nm}\left(\mathrm{OD}_{600}\right)$ was measured at the indicated times in the presence of various stresses. Survival under heat shock stress at $50^{\circ} \mathrm{C}$ was determined by the number of colony forming units during the time indicated. Statistical analyses were performed using unpaired two-tailed $t$-tests. $P$-values are only shown where significant differences were found. ${ }^{*} P<0.05$ and ${ }^{* *} P<0.01$.

\section{CLONING, EXPRESSION AND PURIFICATION OF MsmHr IN ESCHERICHIA COLI}

The coding sequence of $m s m H r$ was amplified from M. smegmatis $\mathrm{mc}^{2} 155$ genomic DNA and cloned into the expression vector pET23b (+) (Novagen, USA), in-frame fused with a C-terminal 6xHis-tag sequence to generate the plasmid pET23b-msmHr, which was transformed into E. coli BL21 (AI) (Invitrogen, USA) for expression. Recombinant $\mathrm{MsmHr}$ was induced by incubation with $0.1 \%$ arabinose at $28^{\circ} \mathrm{C}$ for $3 \mathrm{~h}$. Cells were harvested by centrifugation at $10,000 \mathrm{~g}$ for $5 \mathrm{~min}$, resuspended in lysis buffer (20 mM Tris- $\mathrm{HCl}$ pH 8.0; $1 \mathrm{M} \mathrm{NaCl}, 10 \%$ (v/v) glycerol, $20 \mathrm{mM}$ imidazole, $0.1 \%$ (v/v) Triton X-100, $1 \mathrm{mM}$ phenylmethylsulfonyl fluoride (PMSF), $1 \mathrm{mg} / \mathrm{ml}$ lysozyme) and lysed by sonication. Lysates were centrifuged at $12,000 \mathrm{~g}$ for $30 \mathrm{~min}$ at $4^{\circ} \mathrm{C}$ to remove debris before purification. The supernatants were incubated with Ni-NTA agarose (Qiagen, USA) with rotation $(15 \mathrm{~g}$ ) for $4 \mathrm{~h}$ at $4^{\circ} \mathrm{C}$. Beads were then washed three times with washing buffer (20 mM Tris- $\mathrm{HCl} \mathrm{pH} 8.0,0.5 \mathrm{M} \mathrm{NaCl}, 10 \%$ (v/v) glycerol, $50 \mathrm{mM}$ imidazole, 0.1\% (v/v) Triton X-100, $1 \mathrm{mM}$ PMSF, $25 \mathrm{mM} \mathrm{MgCl} 2$ ). The proteins were eluted with elution buffer $(50 \mathrm{mM}$ Tris- $\mathrm{HCl}$ $\mathrm{pH} 7.5,0.5 \mathrm{M} \mathrm{NaCl}, 25 \mathrm{mM} \mathrm{MgCl}_{2}, 10 \%$ (v/v) glycerol, $400 \mathrm{mM}$ imidazole) and protein concentration was measured using the bicinchoninic acid protein assay reagent and a bovine serum albumin standard. Purified protein was examined using 12\% sodium dodecyl sulfate polyacrylaminde gel electrophoresis to verify molecular weight and purity (Figure S2).

\section{SPECTROPHOTOMETRIC AND CIRCULAR DICHROIC (CD) ANALYSIS OF MsmHr}

Purified MsmHr was diluted in $20 \mathrm{mM}$ Tris- $\mathrm{Cl}$ buffer ( $\mathrm{pH} 7.5$ ). Deoxy samples were obtained by adding a 10 -fold molar excess of $\mathrm{Na}_{2} \mathrm{~S}_{2} \mathrm{O}_{4}$ to MsmHr. UV-Vis spectrophotometric spectra were obtained in $1 \mathrm{~mm}$ path length quartz cuvettes on a UV-2802H UV-Vis spectrophotometer (Unico Shanghai Instruments Co., Ltd., China). Spectra of deoxy-MsmHr were collected in an anaerobic incubator (Shanghai Yuejin Medicial Instruments Co., Ltd, China). CD measurements were performed using a Chirascan Circular Dichroism Spectrometer (Applied Photophysics Ltd. $\mathrm{UK})$. The analysis software provided with the instrument was used for analysis of the results.

\section{DETERMINATION OF THE MINIMUM INHIBITORY CONCENTRATION OF ISONIAZID IN M. SMEGMATIS}

The susceptibility of M. smegmatis to isoniazid (INH) was determined using the broth microdilution method (Wallace et al., 1986). After two-fold dilutions of INH in 7H9 supplemented with ADS enrichment and 0.5\% (v/v) glycerol, $40-\mu \mathrm{l}$ aliquots were mixed with $40 \mu \mathrm{l}$ of $M$. smegmatis suspension $\left(10^{5} \mathrm{cells} / \mathrm{ml}\right)$ and deposited into wells of 96 -well microtiter plates. The highest concentration of INH was $100 \mu \mathrm{g} / \mathrm{ml}$. Plates were incubated at $37^{\circ} \mathrm{C}$ for 2 days and $\mathrm{OD}_{600}$ values of cultures were then measured using a microplate reader (FLUOstar OPTIMA, BMG Labtech). The minimum inhibitory concentration (MIC) was defined as the lowest concentration of drug that inhibited the visible bacterial growth of M. smegmatis after a 2-day incubation $\left(\mathrm{OD}_{600}<0.05\right)$. INH susceptibility tests were repeated at least 3 times.

\section{RNA ISOLATION, RT-PCR AND QUANTITATIVE PCR}

Log phase cultures $\left(\mathrm{OD}_{600}=0.8-1.0\right)$ of all tested strains were diluted 1:100 in 7H9 media supplemented with ADS enrichment, $0.5 \%(\mathrm{v} / \mathrm{v})$ glycerol and $0.05 \%(\mathrm{v} / \mathrm{v})$ Tween 80 . Strains were cultured until the $\mathrm{OD}_{600}$ reached 0.3 and then divided into control and treatment groups. In the treatment group, the cells were treated with $5 \mathrm{mM} \mathrm{H} \mathrm{H}_{2} \mathrm{O}_{2}$ for $30 \mathrm{~min}$, and then collected by centrifugation at $12,000 \mathrm{~g}$. Bacterial pellets were resuspended in TRIzol (Invitrogen, USA) and RNA was purified according to the manufacturer's instructions. cDNA was synthesized using the SuperScriptTM III First-Strand Synthesis System (Invitrogen, USA). Quantitative real-time PCR (qRT-PCR) was performed in a Bio-Rad iCycler using $2 x$ SYBR real-time PCR pre-mix (Takara Biotechnology Inc., Japan). The following cycling program was used: $95^{\circ} \mathrm{C}$ for $1.5 \mathrm{~min}$ followed by 40 cycles of $95^{\circ} \mathrm{C}$ for $10 \mathrm{~s}, 60^{\circ} \mathrm{C}$ for $15 \mathrm{~s}$, and $72^{\circ} \mathrm{C}$ for $15 \mathrm{~s}$, followed for $72^{\circ} \mathrm{C}$ for 6 min. M. smemgatis rpoD encoding RNA polymerase sigma factor SigA was selected as a reference to normalize gene expression. The $2^{-\Delta \Delta C T}$ method was used (Livak and Schmittgen, 2001) to evaluate the relative gene expression in different strains and/or different treatments. Primers used are listed in Table S2.

\section{CONSTRUCTION OF PROMOTER-IacZ FUSION EXPRESSION VECTORS}

SigF is reported to be transcribed from two promoters, $\mathrm{P}_{\text {msmeg_1802 }}$ and $\mathrm{P}_{r b s w}$ (Gebhard et al., 2008). To construct the 
$\mathrm{P}_{\text {msmeg_1802-lacZ }}$ and $\mathrm{P}_{r b s W}$-lacZ plasmids, we used the reported primer pairs PsigFF/PsigFR and P1802F/P1802R (Gebhard et al., 2008), and $\mathrm{P}_{m s m H r}$-lacZ using $\mathrm{P} 2415 \mathrm{~F} / \mathrm{P} 2415 \mathrm{R}$ (Supplemental Table S2). The promoter sequences of sigF, msmeg_1802 and $m s m H r$ were then cloned into the upstream region of the lacZ gene in pLACZint (Vasudeva-Rao and McDonough, 2008), generating the plasmids $\mathrm{P}_{r b s W}$-lacZ, $\mathrm{P}_{\text {msmeg_1802-lacZ }}$ and $\mathrm{P}_{m s m H r}$-lacZ, respectively.

\section{$\beta$-GALACTOSIDASE (LACZ) ACTIVITY ASSAY}

The $\beta$-galactosidase activity of various strains were determined as described previously (Gebhard et al., 2008). Briefly, cultures were collected at early logarithmic phase $\left(\mathrm{OD}_{600} \approx 0.3\right)$ and resuspended in $\mathrm{Z}$ buffer $\left(60 \mathrm{mM} \mathrm{Na} \mathrm{HPO}_{4}, 40 \mathrm{mM} \mathrm{NaH} \mathrm{PO}_{4}\right.$, $10 \mathrm{mM} \mathrm{KCl}, 1 \mathrm{mM} \mathrm{MgSO}_{4}$ and $50 \mathrm{mM} \beta$-mercaptoethanol). Cells were then lysed using a Fastprep bead-beater (Biospec). The enzyme reaction was initiated by adding ortho-nitrophenyl$\beta$-D-galactopyranoside $(2 \mathrm{mg} / \mathrm{ml})$ and terminated by adding $\mathrm{Na}_{2} \mathrm{CO}_{3}(0.8 \mathrm{M})$. $\beta$-galactosidase activity was assessed by measuring the $\mathrm{OD}_{420}$ value of the reactions mixtures. Assays were performed in triplicate, and the Miller units (MU) were calculated as follows: $1000 \times \mathrm{OD}_{420} /\left(\mathrm{OD}_{600}\right.$ of assayed culture $\times$ assayed volume $\times$ time).

\section{CONSTRUCTION OF msmHr POINT MUTANTS}

Mutation of specific amino acids was incorporated into the hemerythrin-like domain of $m s m H r$ in pMV261- $m s m H r$ by mismatched PCR primers (Table S2). Site-directed mutagenesis was performed following using a QuikChange ${ }^{\circledR}$ Site-Directed Mutagenesis Kit (Stratagene) according to the manufacturer's instructions. Mutant clones were confirmed by DNA sequencing (BGI-Shenzhen, Shenzhen China). pMV261-msmHr mutants were transformed into M. smegmatis $\mathrm{mc}^{2} 155$. Mutated sites are as follows (altered amino acids are in underlined bold font):

$$
\begin{aligned}
& \text { H1M: }{ }^{55} \text { AVHETAEEMV }{ }^{65} \rightarrow{ }^{55} \text { AVLETAAAMMV }{ }^{65} \\
& \text { H2M: }{ }^{86} \text { EEHKAKQQLS }{ }^{96} \rightarrow{ }^{86} \text { EELKAKAALS }^{96} \\
& \text { H3M: }{ }^{122} \text { AA } \underline{\text { HEEAEEFV }}{ }^{132} \rightarrow{ }^{122} \text { AALEEAㅍA FV }{ }^{132}
\end{aligned}
$$

\section{RESULTS}

\section{MsmHr IS A BACTERIAL HEMERYTHRIN-LIKE PROTEIN}

Detoxification strategies for scavenging host immune defense system-derived $\mathrm{H}_{2} \mathrm{O}_{2}$ are important for the intracellular survival of mycobacterial pathogens. Expression of Fe-related proteins, such as the Fe-S cluster transcription factor WhiB3, and hemeiron sensors DosS and DosT, is an important strategy for regulating redox balance (Bhat et al., 2012). Hemerythrin proteins are iron-binding proteins known to be involved in oxygen transport and storage, but their biological functions in mycobacteria have yet to be elucidated. Three proteins in M. smegmatis, MsmHr, Msmeg_3312 and Msmeg_6612, are predicted to be hemerythrinlike proteins, however, as preliminary experiments indicated that only $\mathrm{MsmHr}$ is related to the $\mathrm{H}_{2} \mathrm{O}_{2}$ response (data not shown), we focused our attention on $\mathrm{MsmHr}$.

We first constructed a multiple alignment of $\mathrm{MsmHr}$ with other hemerythrin-like proteins from different bacterial species (Figure 1A). Residues H24, H57, E61, H66, H88, H121, and
E126 (numbering based on the MsmHr sequence) matched the characteristic motifs H...HxxxE ...HxxxH...HxxxxD/E of hemerythrin domains. The secondary structure predicted by SWISS-MODEL (http://swissmodel.expasy.org/) (Guex and Peitsch, 1997; Schwede et al., 2003; Arnold et al., 2006; Kiefer et al., 2009) suggested that MsmHr has a typical hemerythrin structure with four $\alpha$-helices (residues 16-40, 41-68, 80-103, and 104-132) (Figure 1B).

To confirm the predicted helical structure of $\mathrm{MsmHr}$, we purified MsmHr-His 6 protein from E. coli. Circular dichroism (CD) spectra of the E. coli-purified MsmHr showed two minima at 208 and $222 \mathrm{~nm}$ (Figure 1C). Such a pattern, which is characteristic of protein $\alpha$-helical structures, is typical of the circular dichroism spectra of previously analyzed bacterial hemerythrins (Wirstam et al., 2003). We also performed a CD analysis of gelactin AAL (Agrocybe aegerita lectin, PDB 2ZGU), a protein which consists mainly of $\beta$-sheets. The CD spectra showed only one minima at $210 \mathrm{~nm}$ (Supplemental Figure S3). The UV-visible absorption spectra of MsmHr showed peaks at 327 and $376 \mathrm{~nm}$, a pattern ascribable to the di-iron-center of hemerythrin-like proteins (Karlsen et al., 2005). Absorbance peaks were abrogated upon reduction with $\mathrm{Na}_{2} \mathrm{~S}_{2} \mathrm{O}_{4}$ to generate the deoxy form by removing oxygen (Figure 1D). Since $\mathrm{MsmHr}$ has no Trp and only one Phe, UV/Vis spectrophotometric analysis of the purified protein did not detect absorbance at $280 \mathrm{~nm}$ (Figure 1D inset). Taken together, these bioinformatics, CD and spectrophotometric results strongly suggest that $\mathrm{MsmHr}$ is a hemerythrin-like protein.

\section{MsmHr IS INVOLVED IN THE $\mathrm{H}_{\mathbf{2}} \mathrm{O}_{\mathbf{2}}$ STRESS RESPONSE}

To define the biological functions of $\mathrm{MsmHr}$, a deletion mutant, $\Delta m s m H r$, was generated by specialized transduction (Bardarov et al., 2002) (Figure 2A). The loss of $m s m H r$ was confirmed by PCR (Figure 2A) and no $m s m H r$ mRNA was detected in $\Delta m s m H r$ (Figure 2B). To determine if deletion of $m s m H r$ had polar effects on the msmeg_2414 and msmeg_2416 genes, their mRNA levels were compared in the wild type $\mathrm{mc}^{2} 155$ and $\Delta m s m H r$ strains by RT-PCR. Statistically significant differences in msmeg_2414 and msmeg_2416 mRNA were not detected (Figure 2B), indicating that $m s m H r$ knockout did not affect the transcriptional levels of msmeg_2414 and msmeg_2416.

We then compared the growth rates of the M. smegmatis parental strain $\mathrm{mc}^{2} 155$ with the MsmHr-deficient mutant $\Delta m s m H r$ in both $7 \mathrm{H} 9$ rich medium and Sauton's minimal medium. No growth abnormalities were detected in $\Delta m s m H r$ relative to $\mathrm{mc}^{2} 155$, demonstrating that $\mathrm{MsmHr}$ does not influence $M$. smegmatis growth in rich $(7 \mathrm{H} 9)$ or minimal medium (Sauton) (Figure 3A). To identify possible biological roles of $\mathrm{MsmHr}$, the growth kinetics and survival of $\Delta m s m H r$ were examined under various stress conditions, including NO, hypoxia, $\mathrm{H}_{2} \mathrm{O}_{2}$, heat shock, and acidic $\mathrm{pH}$. No growth defects in $\Delta m s m H r$ were detected under the conditions tested, with the exception of $\mathrm{H}_{2} \mathrm{O}_{2}$ stress (Figure 3B). $\Delta m s m H r$ exhibited mild $\mathrm{H}_{2} \mathrm{O}_{2}$ resistance compared to the wild type $\mathrm{mc}^{2} 155$ strain after treatment with $5 \mathrm{mM} \mathrm{H}_{2} \mathrm{O}_{2}$ for $3 \mathrm{~h}$, while no difference in the growth of the two strains was observed under non- $\mathrm{H}_{2} \mathrm{O}_{2}$ treatment conditions. In addition, the resistance phenotype was abrogated in 


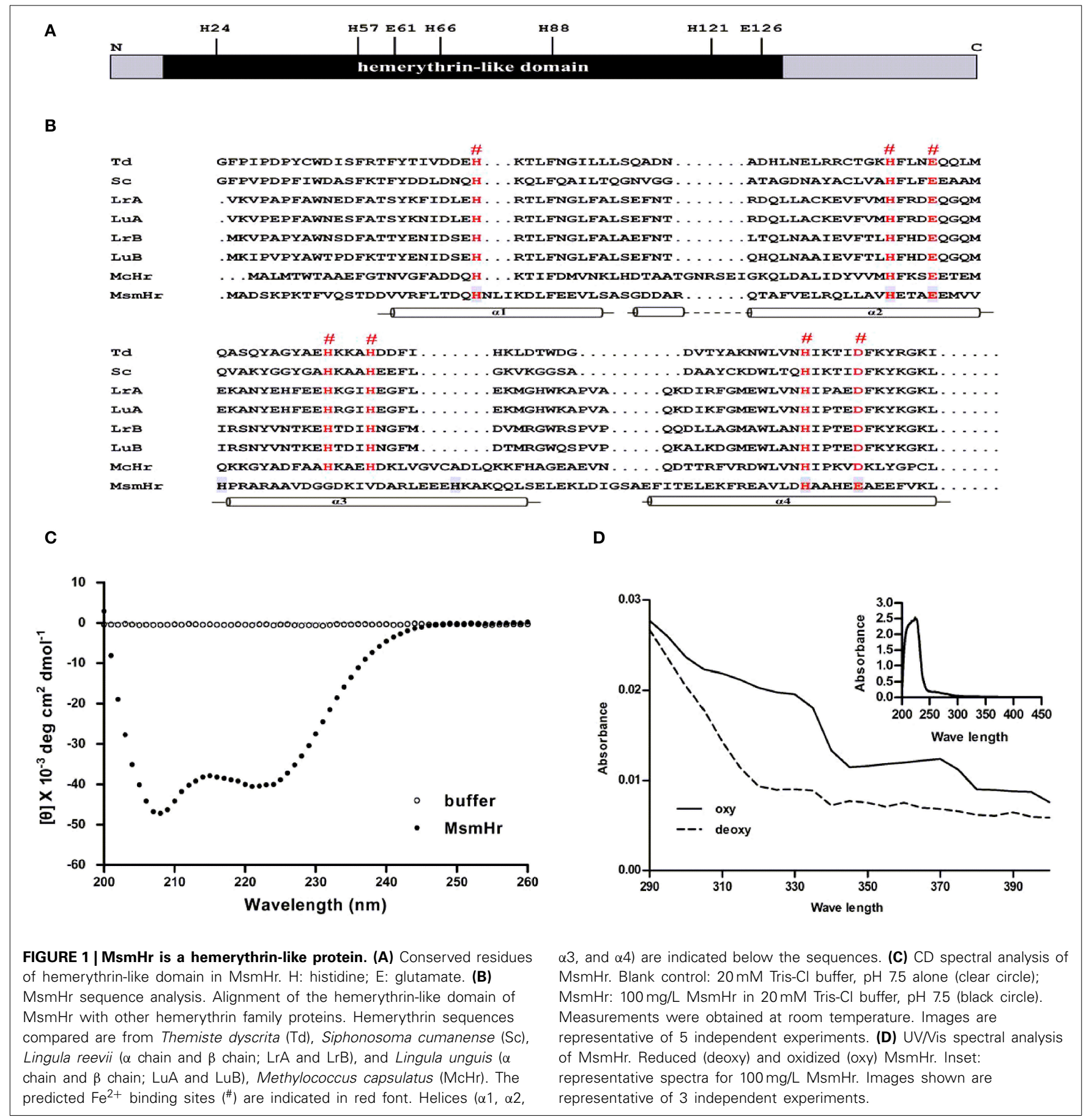

the complemented strain, C- $\Delta m s m H r$ (Figure 3B). Moreover, overexpression of $m s m H r$ in $\mathrm{mc}^{2} 155(\mathrm{O}-m s m H r)$ was associated with $\mathrm{H}_{2} \mathrm{O}_{2}$ susceptibility after treatment with $5 \mathrm{mM} \mathrm{H}_{2} \mathrm{O}_{2}$ for $3 \mathrm{~h}$ (Figure 3B). Differences in mRNA levels of msmeg_2414 and msmeg_2416 in wild type $\mathrm{mc}^{2} 155$ and $\Delta m s m H r$ were not detected after treatment with $\mathrm{H}_{2} \mathrm{O}_{2}$ (Figure 2B). A statistically significant reduction in $m s m H r$ mRNA levels was found between $\mathrm{mc}^{2} 155$ in the presence and absence of $\mathrm{H}_{2} \mathrm{O}_{2}$ (Figure 2B). Taken together, our data suggest that $m s m H r$ plays an inhibitory role in the response to $\mathrm{H}_{2} \mathrm{O}_{2}$ stress.

\section{THE HEMERYTHRIN-LIKE DOMAINS OF MsmHr ARE REOUIRED FOR THE RESPONSE TO $\mathrm{H}_{2} \mathrm{O}_{2}$ STRESS}

To evaluate the potential roles of the hemerythrin-like domain of $\mathrm{MsmHr}$ in the $\mathrm{H}_{2} \mathrm{O}_{2}$ response, we constructed 3 mutants, $\mathrm{H} 1 \mathrm{M}, \mathrm{H} 2 \mathrm{M}$, and $\mathrm{H} 3 \mathrm{M}$, in which the respective conserved amino acid motifs HxxxEE, HxxxQQ, and HxxxEE were all mutated to LxxxAA (Figure 4A). As overexpression of $m s m H r$ showed higher susceptibility to $\mathrm{H}_{2} \mathrm{O}_{2}$, overexpression vector pMV261 containing $m s m H r$ alleles harboring the point mutations $\mathrm{H} 1 \mathrm{M}, \mathrm{H} 2 \mathrm{M}$ or $\mathrm{H} 3 \mathrm{M}$ was introduced into $\mathrm{mc}^{2} 155$ which was then assessed for 


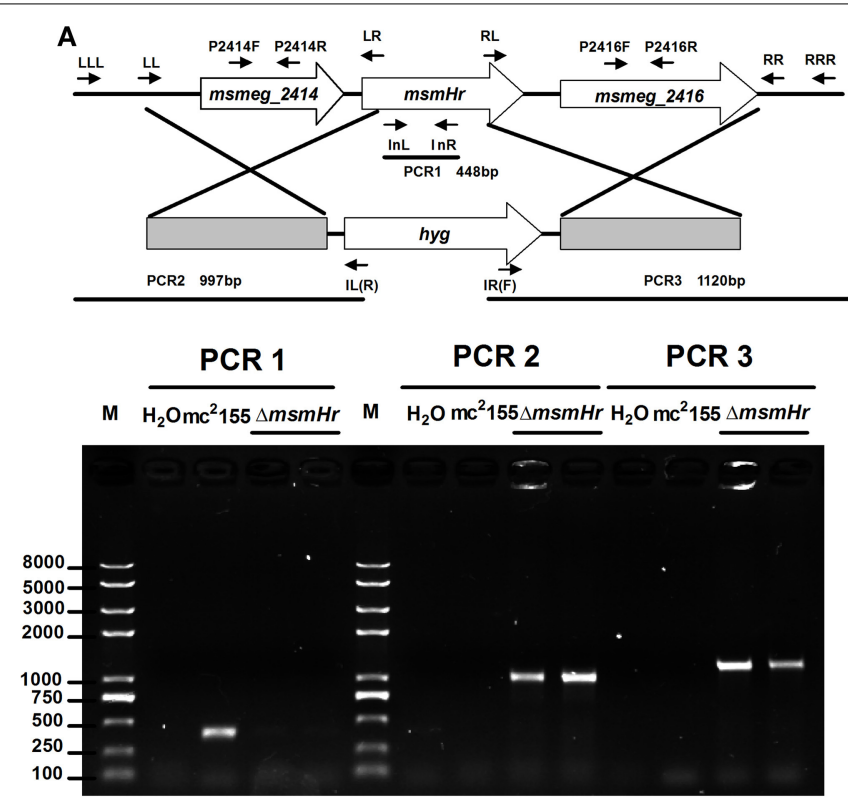

B

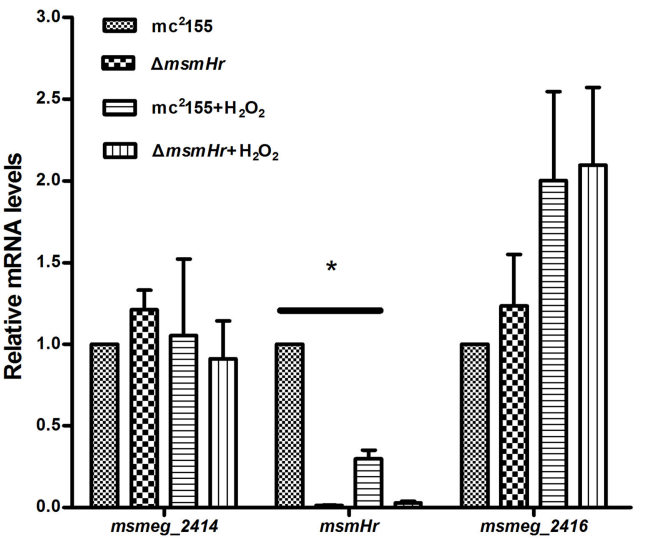

FIGURE 2 | Generation of the $\Delta$ msmHr M. smegmatis strain. (A) Genomic organization of the $m s m H r$ gene locus. (Upper panel) Genes are shown as large arrows in their native orientation. Small arrows represent the forward and reverse primers used for PCR, and sizes of the amplified products are indicated. Location and orientation of the hygromycin cassette are also indicated (Bottom panel). No PCR product was obtained using primers $2415 \mathrm{InL}$ and $2415 \mathrm{InR}$ to amplify the coding sequences of $\mathrm{msmHr}$.
PCR products for the upstream and downstream regions of $m s m H r$ were amplified using the primer pairs 2415LLL/IL(R) and 2415RRR/IR(F), respectively. (B) Effect of $m s m H r$ deletion on msmeg_2414 and msmeg_2416 expression. Quantitative real-time PCR (qRT-PCR) analysis of $m s m H r$ cluster transcription. The primer pairs 2414qF/2414qR and $2416 q F / 2416 q R$ were used for qRT-PCR. Results are shown as the means \pm standard deviations of three replicates $\left({ }^{*} P<0.05\right)$. resistance to $\mathrm{H}_{2} \mathrm{O}_{2}$. All strains overexpressing the corresponding $\mathrm{H} 1 \mathrm{M}, \mathrm{H} 2 \mathrm{M}$ or $\mathrm{H} 3 \mathrm{M}$ mutant $m s m H r$ proteins behaved like $\mathrm{mc}^{2} 155$. By contrast, strains containing intact $\mathrm{ms} m \mathrm{Hr}$ proteins were susceptible to $\mathrm{H}_{2} \mathrm{O}_{2}$ (Figure $4 \mathbf{B}$ ). This result indicates that the hemerythrin-like domain of $\mathrm{MsmHr}$ is required for $\mathrm{H}_{2} \mathrm{O}_{2}$ susceptibility.

\section{MsmHr REPRESSES sigF EXPRESSION THROUGH THE PROMOTER $\mathbf{P}_{\text {rbsw }}$}

There are two independent oxidative stress pathways in mycobacteria: the KatG-, isoniazid (INH)-related pathway and the SigFrelated, INH-unrelated related pathway (Gebhard et al., 2008; Wu et al., 2012). INH is an important first-line anti-mycobacterial pro-drug and is activated by the bacterial catalase-peroxide enzyme encoded by katG (msmeg_3461). Resistance to $\mathrm{H}_{2} \mathrm{O}_{2}$ has been shown to correlate with susceptibility to INH (Bulatovic et al., 2002). To determine which pathway $\mathrm{MsmHr}$ is involved in, we measured the minimum inhibitory concentration (MIC) of INH against $\Delta m s m H r$ and wild type $\mathrm{mc}^{2} 155$. No difference in the MICs of these two strains was detected $(3.125 \mathrm{mg} / \mathrm{L}$ in both $\Delta m s m H r$ and $\left.m^{2} 155\right)$, suggesting that $\mathrm{MsmHr}$ is not involved in the INH-related $\mathrm{H}_{2} \mathrm{O}_{2}$ response. We then examined whether $\mathrm{MsmHr}$ is involved in the SigF-mediated $\mathrm{H}_{2} \mathrm{O}_{2}$ response. As previous studies have shown that $\operatorname{sig} F$ is transcribed from two promoters, we constructed two vectors with the two promoter regions, $\mathrm{P}_{\text {msmeg_1802 }}$ and $\mathrm{P}_{\text {rbsw }}$, fused to lacZ $\left(\mathrm{P}_{\text {msmeg_1802-lac }}\right.$ and $\mathrm{P}_{r b s w}$-lacZ, respectively) (Humpel et al., 2010). We measured the indicated promoter activities at the early logarithmic phase: $\beta$-galactosidase activity associated with $\mathrm{P}_{m s m H r}-$ lac $Z$ was $6.9 \pm$ $0.2 \mathrm{MU}$ in $\mathrm{mc}^{2} 155$ and $7.6 \pm 0.1 \mathrm{MU}$ in $\Delta m s m H r$, indicating that MsmHr does not self-regulate at the transcriptional level. Wild type $\mathrm{mc}^{2} 155$ harboring $\mathrm{P}_{\text {msmeg_1802-lac } Z \text { had a } \beta \text {-galactosidase }}$ activity of 3.6 $\pm 0.3 \mathrm{MU}$, while the activity of $\Delta m s m H r$ harboring $\mathrm{P}_{\text {msmeg_1802-lac }}$ was $3.7 \pm 0.2 \mathrm{MU}$, indicating that $\mathrm{MsmHr}$ does not influence the promoter activity of $\mathrm{P}_{\text {msmeg_1802 }}$ (Figure 5B left panel). In contrast, $\Delta m s m H r$ harboring $\mathrm{P}_{r b s w}$-lacZ had a significantly higher $\beta$-galactosidase activity $(15.7 \pm 1.9 \mathrm{MU})$ than that of wild type $\mathrm{mc}^{2} 155$ (Figure 5B right panel). We also measured the mRNA levels of sigF in $\mathrm{mc}^{2} 155, \Delta m s m H r$ and its complementary strain C- $\Delta m s m H r$. Consistent with results for the promoter, the knockout $m s m H r$ led to a $1.9 \pm 0.2$ fold increase relative to the mRNA level of sigF to wild type $\mathrm{mc}^{2} 155$, while levels of sigF mRNA were not significantly different (Figure 5C). Taken together, our results suggest that $\mathrm{MsmHr}$ affects the mRNA level of sigF via $\mathrm{P}_{r b s w}$.

\section{MsmHr IS NECESSARY FOR THE SigF MEDIATED $\mathrm{H}_{2} \mathrm{O}_{2}$ RESPONSE}

The above results indicate that MsmHr suppresses sigF expression at the early logarithmic phase (Figure 5). We next examined the influence of MsmHr on the SigF-mediated $\mathrm{H}_{2} \mathrm{O}_{2}$ pathway. We compared the mRNA level of sigF between $\mathrm{mc}^{2} 155, \Delta m s m H r$ and the $\Delta m s m H r$ complementary strain C- $\Delta m s m H r$ after $5 \mathrm{mM}$ $\mathrm{H}_{2} \mathrm{O}_{2}$ treatment for $30 \mathrm{~min}$. As shown in Figure 5C, sigF mRNA was induced by $\mathrm{H}_{2} \mathrm{O}_{2}$ in $\mathrm{mc}^{2} 155$, while induction of sigF mRNA by $\mathrm{H}_{2} \mathrm{O}_{2}$ was not detected in $\Delta m s m H r$. The increase in sigF mRNA induced by $\mathrm{H}_{2} \mathrm{O}_{2}$ was restored in $\mathrm{C}-\Delta m s m H r$. These 


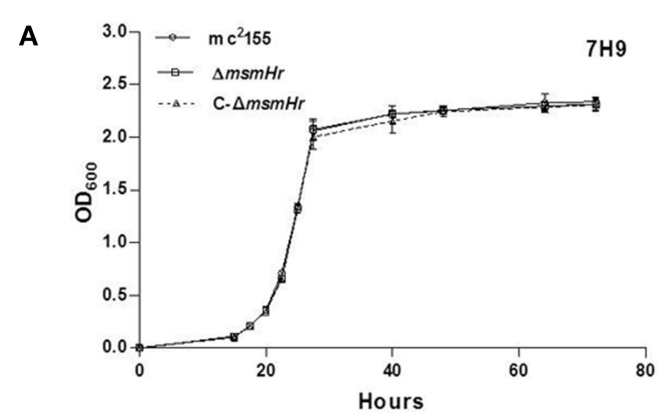

B

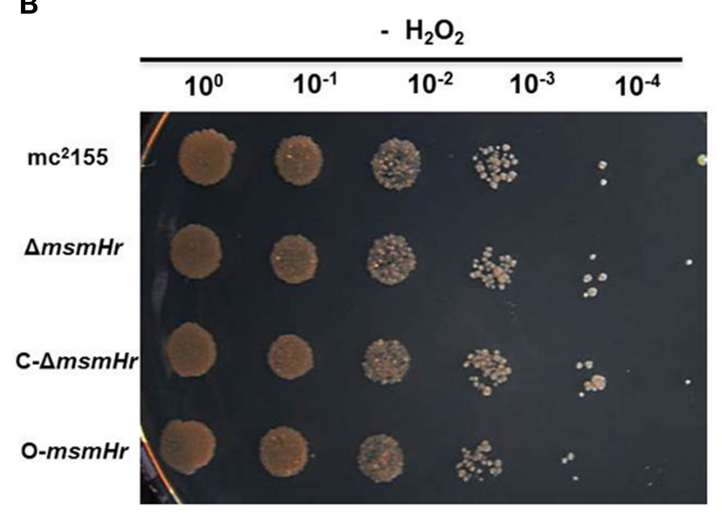

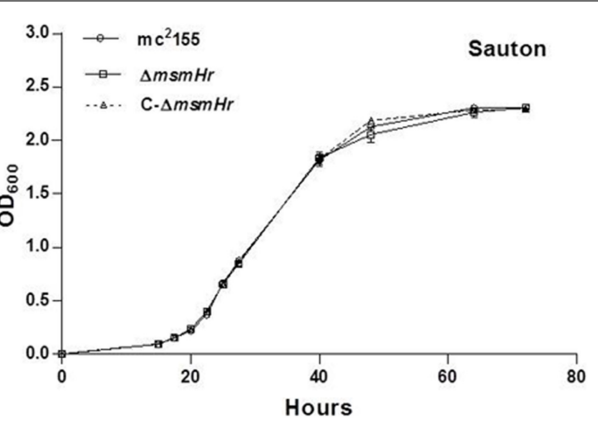

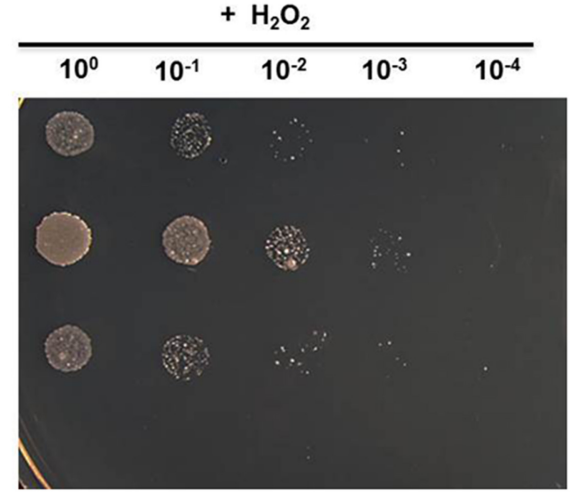

FIGURE 3 | MsmHr is involved in the $\mathbf{H}_{\mathbf{2}} \mathbf{O}_{\mathbf{2}}$ stress response. (A) $\mathrm{MsmHr}$ is not necessary for normal growth. Growth curves of $\mathrm{mc}^{2} 155, \Delta m s m H r$ and the complementary strain $(\mathrm{C}-\Delta m s m H r)$ in $7 \mathrm{H} 9$ rich media (left) and Sauton minimal media (right). The data shown are representative of four independent experiments. (B) MsmHr plays a negative role in the bacterial $\mathrm{H}_{2} \mathrm{O}_{2}$ response. The left panel represents serial dilutions $(1: 10)$ of $m c^{2} 155$, $\Delta m s m H r$, the complemented strain C- $\Delta m s m H r$ and the $m s m H r$ overexpression strain (O-msmHr: pMV261- $\left.m s m H r / m^{2} 155\right)$. Diluted log phase $M$. smegmatis cultures were spotted $(3 \mu \mathrm{l})$ onto solid $7 \mathrm{H} 10$ medium supplemented with $10 \%$ ADS. Right panel, the corresponding strains were spotted on solid 7H10 medium supplemented with 10\% ADS after treatment with $5 \mathrm{mM} \mathrm{H}_{2} \mathrm{O}_{2}$. Photographs were taken after 2-3 days incubation at $37^{\circ} \mathrm{C}$. Images shown are representative of at least 3 experiments. results show that $\mathrm{MsmHr}$ is required for the SigF-mediated response to $\mathrm{H}_{2} \mathrm{O}_{2}$.

In addition, we used qRT-PCR to measure the mRNA levels of redox-related genes in both $\mathrm{mc}^{2} 155$ and $\Delta m s m H r$ in response to $\mathrm{H}_{2} \mathrm{O}_{2}$ treatment, using $r p o D$ mRNA as an internal invariant control (Table S3). We then chose the high $\mathrm{H}_{2} \mathrm{O}_{2}$-induced genes msmeg_4753 and msmeg_1782, which belong to the SigF regulon, to evaluate their mRNA level in response to $\mathrm{H}_{2} \mathrm{O}_{2}$ treatment in $\mathrm{mc}^{2} 155, \Delta s i g F, \Delta m s m H r$ and $\mathrm{C}-\Delta m s m H r$. The level of msmeg_4753 mRNA increased $5.6 \pm 0.9$ fold in $\mathrm{mc}^{2} 155$ after treatment with $\mathrm{H}_{2} \mathrm{O}_{2}$, but induction of msmeg_4753 was abrogated in $\Delta m s m H r$ and $\Delta s i g F$ after treatment with $\mathrm{H}_{2} \mathrm{O}_{2}$ (Figure 6B). In C- $\Delta m s m H r$, an increase in msmeg_4753 RNA was observed in response to $\mathrm{H}_{2} \mathrm{O}_{2}$ (Figure 6B). The level of Msmeg_1782 mRNA increased two-fold in both $\mathrm{mc}^{2} 155$ and $\mathrm{C}-\Delta m s m H r$ when treated with $\mathrm{H}_{2} \mathrm{O}_{2}$, while no changes in mRNA level were observed in response to $\mathrm{H}_{2} \mathrm{O}_{2}$ in $\Delta m s m H r$ and $\Delta$ sigF (Figure 6A). Taken together, this data indicates that $\mathrm{MsmHr}$ is required for the SigF-mediated $\mathrm{H}_{2} \mathrm{O}_{2}$ response.

\section{DISCUSSION}

In this study, we have identified a mycobacterial hemerythrinlike protein $\mathrm{MsmHr}$, which regulates sigF expression via promoter $\mathrm{P}_{\text {rbsw }}$ and is necessary for the SigF-mediated $\mathrm{H}_{2} \mathrm{O}_{2}$ response. To our knowledge, MsmHr is the first hemerythrin-like protein to be characterized in mycobacteria.

Specific roles for hemerythrin-like proteins are just beginning to be characterized (Xiong et al., 2000; Justino et al., 2007; Schaller et al., 2012). On the basis of their sequences, hemerythrin-like proteins have been postulated to have diverse physiological functions related to oxygen and/or iron (Bailly et al., 2008; French et al., 2008). For example, the E. coli hemerythrin-like protein YtfE confers protection against both $\mathrm{NO}$ and $\mathrm{H}_{2} \mathrm{O}_{2}$ stresses (Justino et al., 2005, 2007). Here, however, we did not observe any growth differences between $\mathrm{mc}^{2} 155$ and $\Delta m s m H r$ under NO stress, suggesting that the functions of hemerythrin-like proteins in mycobacteria might be distinct from those in E. coli. The variation in biological functions of hemerythrin-like proteins might be due to different selective evolutionary environments (Saini et al., 2012b; Martin-Duran et al., 2013).

No difference in sensitivity to INH was observed between the wild-type $\mathrm{mc}^{2} 155$ and $\Delta m s m H r$ strains, suggesting that $\mathrm{MsmHr}$ is not involved in the INH-related oxidative stress response pathway but rather in an alternative SigF-related $\mathrm{H}_{2} \mathrm{O}_{2}$ pathway (Gebhard et al., 2008; Wu et al., 2012). It will be interesting to explore why mycobacteria use two-independent $\mathrm{H}_{2} \mathrm{O}_{2}$ scavenging pathways and which sensors trigger each of these signaling pathways. Recent reports show that a hemerythrin-like domain 


\section{A MADSKPKTFVQSTDDVVRFLTDQHNLIKDLFEEVLSASGDDARQTAFVELRQLLAVHETAEEMVV H1M: L AA HPRARAAVDGGDKIVDARLEEEHKAKQQLSELEKLDIGSAEEITELEKFREAVLDHAAHEEAEEF H2M: L AA H3M: L AA \\ VKLSRELDAQELERMTKAVQAAEAIAPTRPHAGVESASLNFAVGPFASMLDRARDLIGSALK}

B

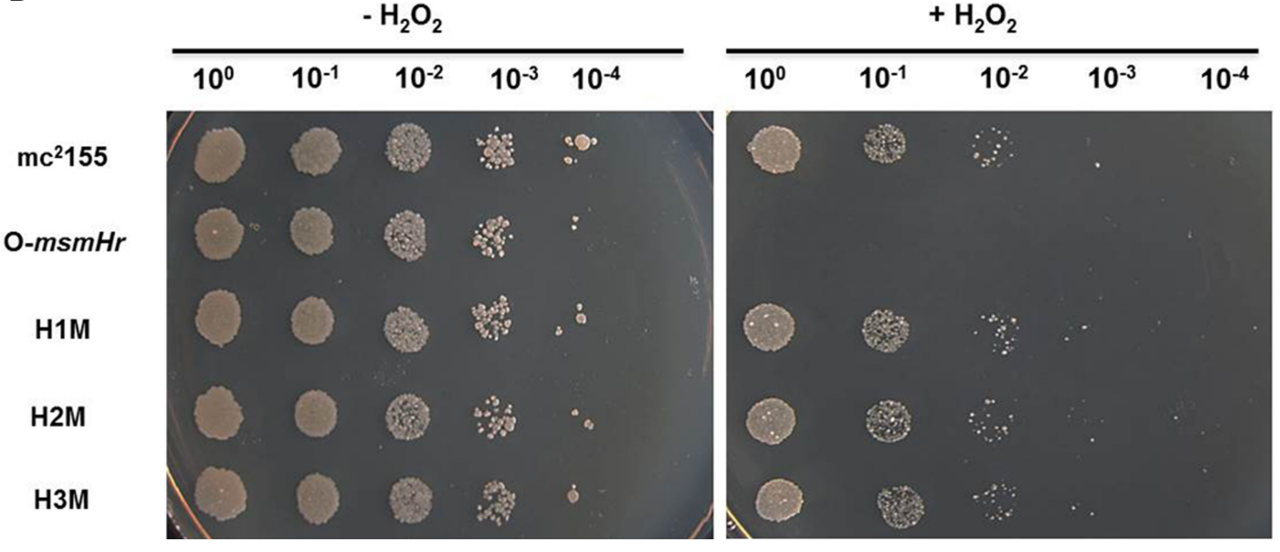

FIGURE 4 | The hemerythrin domain is essential to MsmHr function. (A) The hemerythrin domain (underlined) of $\mathrm{MsmHr}$ and conserved amino acids ( $\mathrm{H}$. . . EE/QQ: red and boxed) in the hemerythrin domain are indicated. Mutations used in the following experiments are indicated under the sequence. (B) Serial dilutions (1:10) of $\mathrm{mc}^{2} 155, \mathrm{pMV} 261-\mathrm{ms} m \mathrm{Hr} / \mathrm{mc}^{2} 155$
(O-msmHr), pMV261-msmHrH1M/mc 155 (H1M), pMV261-msmHrH2M/mc 2155 (H2M) and pMV261- $m s m H r H 3 M / m c^{2} 155$ ( $\mathrm{H} 3 \mathrm{M})$ treated with 0 (left) or $5 \mathrm{mM}$ (right) $\mathrm{H}_{2} \mathrm{O}_{2}$ were spotted $(3 \mu \mathrm{l}$ ) onto solid $7 \mathrm{H} 10$ agar. Photographs were taken after $2-3$ days incubation at $37^{\circ} \mathrm{C}$. Images shown are representative of at least 3 experiments.

\section{A \\ B}
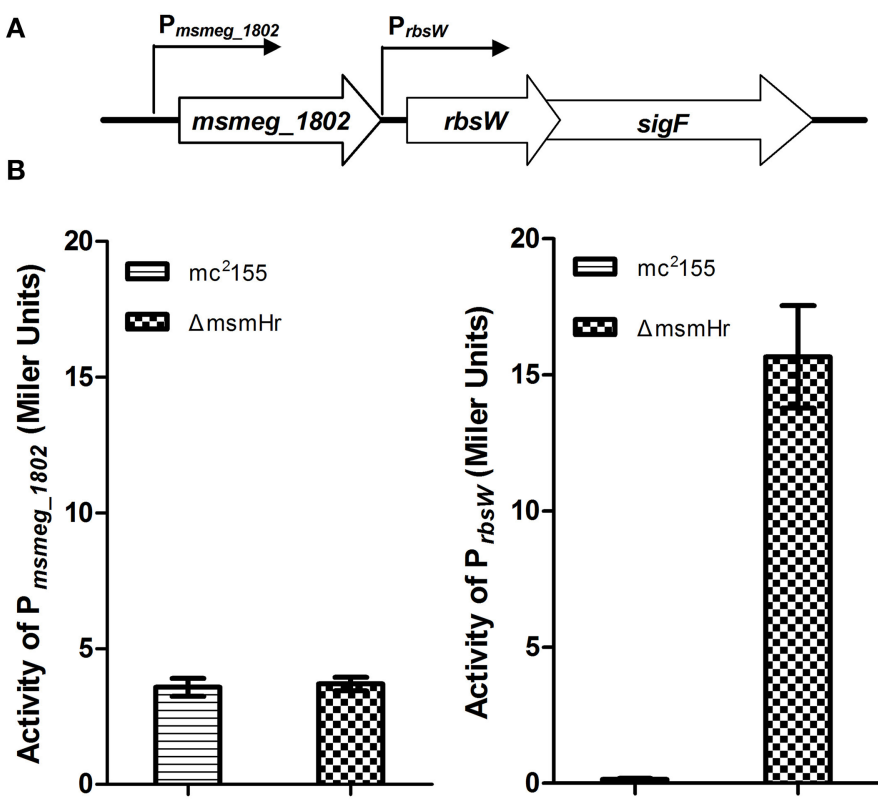

C

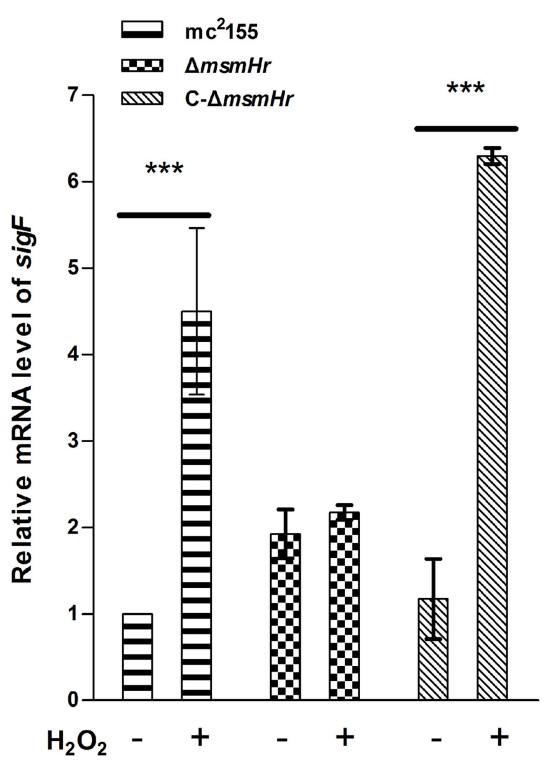

FIGURE 5 | MsmHr regulates sigF expression through the promoter $\mathbf{P}_{\text {rbsw }}$. (A) The genomic organization of the sigf locus. Genes are shown as large arrows in their transcriptional orientation, and the locations of $\mathrm{P}_{\text {msmeg_1802 }}$ and $\mathrm{P}_{\text {rbsw }}$ are indicated. (B) MsmHr negatively regulates the activity of the sigF promoter $\mathrm{P}_{r b s w}$. $\mathrm{P}_{\text {msmeg_ } 1802-l a c Z}$ and $\mathrm{P}_{r b s w}-\mathrm{lac} Z$ were each transformed into $\mathrm{mc}^{2} 155$ and the mutant strain $\Delta m s m H r$. The $\beta$-galactosidase activity was measured when bacterial growth reached an
$\mathrm{OD}_{600}$ of 0.3 . Results representative of 5 independent experiments are shown. (C) The $\mathrm{msmHr}$ deletion is associated with an increase in sigF mRNA levels. Early-phase cultures of $M$. smegmatis $\mathrm{mc}^{2} 155, \Delta m s m H r$ and the complemented strain $\mathrm{C}-\Delta m s m H r$ were treated with $0(-)$ or 5 (+) $\mathrm{mM} \mathrm{H}_{2} \mathrm{O}_{2}$ for $30 \mathrm{~min}$, and sigf expression levels were determined by qRT-PCR. Results are shown as the mean \pm standard deviations of three replicates $(* * * P<0.01)$. 

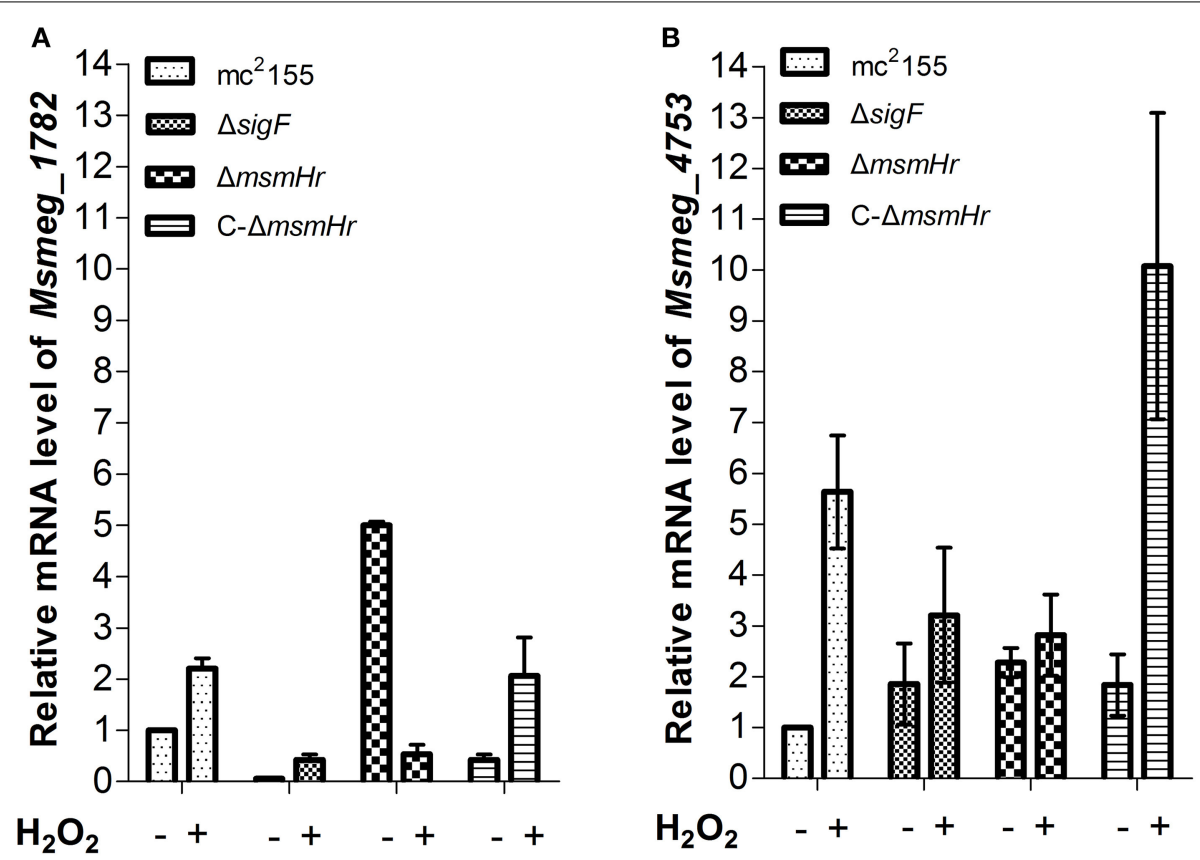

FIGURE 6 | (A) Corresponding mRNA level of msmeg_ 1782 was determined by qRT-PCR. (B) Corresponding mRNA level of msmeg_4753 was determined by qRT-PCR. Bacteria were treated as described in Figure 5. Data shown are representative of three independent experiments.

of FBXL5 can sense if endogenous iron is limiting and respond to iron stress in the mammalian system (Salahudeen et al., 2009; Vashisht et al., 2009). The correlation between iron- and oxygenbinding $\mathrm{MsmHr}$ and SigF-dependent $\mathrm{H}_{2} \mathrm{O}_{2}$ responses needs to be further explored.

The complexity of the transcription regulatory network allows for efficient and prompt change in levels of gene transcription in response to environmental changes. The protein encoded by mycobacterial sigF has closest homology to Streptomyces coelicolor SigF, Bacillus subtilis SigF and B. subtilis SigB (Demaio et al., 1996, 1997; Gebhard et al., 2008). In B. subtilis, sigB is activated upon entry into the stationary phase and by environmental stresses such as heat, oxidative stress and hyper osmosis. The transcription of sigB has been shown to be controlled by two promoters (Wise and Price, 1995). Similarly, SigF may be a potential general stress regulator; SigF is not only activated upon entry into the stationary phase, but is also induced by environmental stresses such as heat shock, acidic $\mathrm{pH}$ and oxidative stress (Wise and Price, 1995; Gebhard et al., 2008). Expression of sigF has been shown to be regulated by two promoters, $\mathrm{P}_{\text {msmeg_1802 }}$ and $\mathrm{P}_{r b s w}$. While promoter $\mathrm{P}_{\text {msmeg_1802 }}$ is known to respond to entry into the stationary phase (Gebhard et al., 2008), the role of $\mathrm{P}_{r b s w}$ is less well understood. In this study, comparisons of the activity of the promoters of $s i g F$ and the mRNA level of sigF in the wild type $\mathrm{mc}^{2} 155$ and mutant $\Delta m s m H r$ strains (Figure 5) showed that $\mathrm{MsmHr}$ regulates sigF expression via the $\mathrm{P}_{r b s w}$ promoter.

We show here that MsmHr is essential for the SigF-mediated $\mathrm{H}_{2} \mathrm{O}_{2}$ response (Figures 5, 6). MsmHr hinders sigF promoter activation and inhibits sig $F$ transcription during normal growth. When $m s m H r$ is deleted, inhibition of $s i g F$ is abrogated, and $s i g F$ maintains a higher transcript level. The transcription level of sigF did not vary in response to $\mathrm{H}_{2} \mathrm{O}_{2}$ treatment in mutant $\Delta m s m H r$ strains, possibly because the mRNA level of sigF was maintained at a higher level in $\Delta m s m H r$ (Figure 5). We measured mRNA level changes of members of the SigF-regulon, msmeg_4753 and msmeg_1782, before, between, and after treatment with $\mathrm{H}_{2} \mathrm{O}_{2}$. Our data show that in wild type $\mathrm{mc}^{2} 155$, mRNA levels of both msmeg_4753 and msmeg_1782 increased in response to $\mathrm{H}_{2} \mathrm{O}_{2}$ treatment, but no specific response to $\mathrm{H}_{2} \mathrm{O}_{2}$ was observed in $\Delta s i g F$ and $\Delta m s m H r$ (Figure 6), suggesting that $\mathrm{MsmHr}$ is required for induction of msmeg_4753 and msmeg_1782 transcription in response to $\mathrm{H}_{2} \mathrm{O}_{2}$. The presence of inhibitory protein MsmHr suggests that the transcriptional regulation of SigF itself and the SigF regulon, or at least part of the SigF regulon, is based on the balance between the activation and inhibition of the $\mathrm{H}_{2} \mathrm{O}_{2}$ response. In $\Delta m s m H r$, the inhibition of $s i g F$ is abrogated and sigF maintains high transcript levels. The expression of one of the SigF regulon genes, $\mathrm{msmeg}_{-} 1782$, is high in $\Delta m s m H r$ during normal growth compared with $\mathrm{mc}^{2} 155$, but decreases in response to $\mathrm{H}_{2} \mathrm{O}_{2}$ treatment. This is consistent with the finding that $\mathrm{MsmHr}$ is necessary for the SigF-dependent $\mathrm{H}_{2} \mathrm{O}_{2}$ pathway and that the response of sigF to $\mathrm{H}_{2} \mathrm{O}_{2}$ is also abrogated in the absence of $m s m H r$.

In summary, we have identified a mycobacterial hemerythrinlike protein that negatively regulates $\mathrm{SigF}$ via the $\mathrm{P}_{r b s w}$ promoter in response to oxidative stress.

\section{ACKNOWLEDGMENTS}

We thank Defeng Li for the gift of the protein gelactin AAL. This work was supported by the Ministry of Science and Technology of China (2014CB744402 and 2012CB518700). 


\section{SUPPLEMENTARY MATERIAL}

The Supplementary Material for this article can be found online at: http://www.frontiersin.org/journal/10.3389/fmicb. 2014.00800/abstract

\section{REFERENCES}

Arnold, K., Bordoli, L., Kopp, J., and Schwede, T. (2006). The SWISS-MODEL workspace: a web-based environment for protein structure homology modelling. Bioinformatics 22, 195-201. doi: 10.1093/bioinformatics/bti770

Bailly, X., Vanin, S., Chabasse, C., Mizuguchi, K., and Vinogradov, S. N. (2008). A phylogenomic profile of hemerythrins, the nonheme diiron binding respiratory proteins. BMC Evol. Biol. 8:244. doi: 10.1186/1471-2148-8-244

Bardarov, S., Bardarov, S. Jr., Pavelka, M. S. Jr., Sambandamurthy, V., Larsen, M., Tufariello, J., et al. (2002). Specialized transduction: an efficient method for generating marked and unmarked targeted gene disruptions in Mycobacterium tuberculosis, M. bovis BCG and M. smegmatis. Microbiology 148, 3007-3017.

Beaucher, J., Rodrigue, S., Jacques, P. E., Smith, I., Brzezinski, R., and Gaudreau, L. (2002). Novel Mycobacterium tuberculosis anti-sigma factor antagonists control sigmaF activity by distinct mechanisms. Mol. Microbiol. 45, 1527-1540. doi: 10.1046/j.1365-2958.2002.03135.x

Bhat, S. A., Singh, N., Trivedi, A., Kansal, P., Gupta, P., and Kumar, A. (2012). The mechanism of redox sensing in Mycobacterium tuberculosis. Free Radic. Biol. Med. 53, 1625-1641. doi: 10.1016/j.freeradbiomed.2012.08.008

Bulatovic, V. M., Wengenack, N. L., Uhl, J. R., Hall, L., Roberts, G. D., Cockerill, F. R. III. et al. (2002). Oxidative stress increases susceptibility of Mycobacterium tuberculosis to isoniazid. Antimicrob. Agents Chemother. 46, 2765-2771. doi: 10.1128/AAC.46.9.2765-2771.2002

Burian, J., Ramon-Garcia, S., Sweet, G., Gomez-Velasco, A., Av-Gay, Y., and Thompson, C. J. (2012). The mycobacterial transcriptional regulator whiB7 gene links redox homeostasis and intrinsic antibiotic resistance. J. Biol. Chem. 287, 299-310. doi: 10.1074/jbc.M111.302588

Chen, K. H., Wu, H. H., Ke, S. F., Rao, Y. T., Tu, C. M., Chen, Y. P., et al. (2012). Bacteriohemerythrin bolsters the activity of the particulate methane monooxygenase (pMMO) in Methylococcus capsulatus (Bath). J. Inorg. Biochem. 111, 10-17. doi: 10.1016/j.jinorgbio.2012.02.019

Demaio, J., Zhang, Y., Ko, C., and Bishai, W. R. (1997). Mycobacterium tuberculosis sigF is part of a gene cluster with similarities to the Bacillus subtilis sigF and sigB operons. Tuber. Lung Dis. 78, 3-12.

Demaio, J., Zhang, Y., Ko, C., Young, D. B., and Bishai, W. R. (1996). A stationaryphase stress-response sigma factor from Mycobacterium tuberculosis. Proc. Natl. Acad. Sci. U.S.A. 93, 2790-2794.

Fang, F. C. (2004). Antimicrobial reactive oxygen and nitrogen species: concepts and controversies. Nat. Rev. Microbiol. 2, 820-832. doi: 10.1038/nrmicro1004

Farhana, A., Guidry, L., Srivastava, A., Singh, A., Hondalus, M. K., and Steyn, A. J. (2010). Reductive stress in microbes: implications for understanding Mycobacterium tuberculosis disease and persistence. Adv. Microb. Physiol. 57, 43-117. doi: 10.1016/B978-0-12-381045-8.00002-3

French, C. E., Bell, J. M., and Ward, F. B. (2008). Diversity and distribution of hemerythrin-like proteins in prokaryotes. FEMS Microbiol. Lett. 279, 131-145. doi: 10.1111/j.1574-6968.2007.01011.x

Gebhard, S., Humpel, A., McLellan, A. D., and Cook, G. M. (2008). The alternative sigma factor SigF of Mycobacterium smegmatis is required for survival of heat shock, acidic pH and oxidative stress. Microbiology 154, 2786-2795. doi: 10.1099/mic.0.2008/018044-0

Guex, N., and Peitsch, M. C. (1997). SWISS-MODEL and the Swiss-PdbViewer: an environment for comparative protein modeling. Electrophoresis 18, 2714-2723. doi: 10.1002/elps.1150181505

Humpel, A., Gebhard, S., Cook, G. M., and Berney, M. (2010). The SigF regulon in Mycobacterium smegmatis reveals roles in adaptation to stationary phase, heat, and oxidative stress. J. Bacteriol. 192, 2491-2502. doi: 10.1128/JB.00035-10

Imlay, J. A. (2008). Cellular defenses against superoxide and hydrogen peroxide. Annu. Rev. Biochem. 77, 755-776. doi: 10.1146/annurev.biochem.77.061606. 161055

Imlay, J. A. (2013). The molecular mechanisms and physiological consequences of oxidative stress: lessons from a model bacterium. Nat. Rev. Microbiol. 11, 443-454. doi: 10.1038/nrmicro3032

Isaza, C. E., Silaghi-Dumitrescu, R., Iyer, R. B., Kurtz, D. M. Jr., and Chan, M. K. (2006). Structural basis for O2 sensing by the hemerythrin-like domain of a bacterial chemotaxis protein: substrate tunnel and fluxional $\mathrm{N}$ terminus. Biochemistry 45, 9023-9031. doi: 10.1021/bi0607812

Jacobs, W. R. Jr., Kalpana, G. V., Cirillo, J. D., Pascopella, L., Snapper, S. B., Udani, R. A., et al. (1991). Genetic systems for mycobacteria. Meth. Enzymol. 204, 537-555.

Justino, M. C., Almeida, C. C., Teixeira, M., and Saraiva, L. M. (2007). Escherichia coli di-iron YtfE protein is necessary for the repair of stress-damaged ironsulfur clusters. J. Biol. Chem. 282, 10352-10359. doi: 10.1074/jbc.M6106 56200

Justino, M. C., Vicente, J. B., Teixeira, M., and Saraiva, L. M. (2005). New genes implicated in the protection of anaerobically grown Escherichia coli against nitric oxide. J. Biol. Chem. 280, 2636-2643. doi: 10.1074/jbc.M411070200

Kao, W. C., Chen, Y. R., Yi, E. C., Lee, H., Tian, Q., Wu, K. M., et al. (2004). Quantitative proteomic analysis of metabolic regulation by copper ions in Methylococcus capsulatus (Bath). J. Biol. Chem. 279, 51554-51560. doi: 10.1074/jbc.M408013200

Karlsen, O. A., Ramsevik, L., Bruseth, L. J., Larsen, O., Brenner, A., Berven, F. S. et al. (2005). Characterization of a prokaryotic haemerythrin from the methanotrophic bacterium Methylococcus capsulatus (Bath). FEBS J. 272, 2428-2440. doi: 10.1111/j.1742-4658.2005.04663.x

Kiefer, F., Arnold, K., Kunzli, M., Bordoli, L., and Schwede, T. (2009). The SWISS-MODEL Repository and associated resources. Nucleic Acids Res. 37, D387-D392. doi: 10.1093/nar/gkn750

Kumar, A., Farhana, A., Guidry, L., Saini, V., Hondalus, M., and Steyn, A. J. (2011). Redox homeostasis in mycobacteria: the key to tuberculosis control? Expert Rev Mol. Med. 13, e39. doi: 10.1017/S1462399411002079

Kumar, A., Toledo, J. C., Patel, R. P., Lancaster, J. R. Jr., and Steyn, A. J. (2007). Mycobacterium tuberculosis DosS is a redox sensor and DosT is a hypoxia sensor. Proc. Natl. Acad. Sci. U.S.A. 104, 11568-11573. doi: 10.1073/pnas.0705054104

Livak, K. J., and Schmittgen, T. D. (2001). Analysis of relative gene expression data using real-time quantitative PCR and the 2(-Delta Delta C(T)) Method. Methods 25, 402-408. doi: 10.1006/meth.2001.1262

Martin-Duran, J. M., De Mendoza, A., Sebe-Pedros, A., Ruiz-Trillo, I., and Hejnol, A. (2013). A broad genomic survey reveals multiple origins and frequent losses in the evolution of respiratory hemerythrins and hemocyanins. Genome Biol. Evol. 5, 1435-1442. doi: 10.1093/gbe/evt102

Michele, T. M., Ko, C., and Bishai, W. R. (1999). Exposure to antibiotics induces expression of the Mycobacterium tuberculosis sigF gene: implications for chemotherapy against mycobacterial persistors. Antimicrob. Agents Chemother. $43,218-225$.

Onoda, A., Okamoto, Y., Sugimoto, H., Shiro, Y., and Hayashi, T. (2011). Crystal structure and spectroscopic studies of a stable mixed-valent state of the hemerythrin-like domain of a bacterial chemotaxis protein. Inorg. Chem. 50, 4892-4899. doi: 10.1021/ic2001267

Rawat, M., Newton, G. L., Ko, M., Martinez, G. J., Fahey, R. C., and Av-Gay, Y. (2002). Mycothiol-deficient Mycobacterium smegmatis mutants are hypersensitive to alkylating agents, free radicals, and antibiotics. Antimicrob. Agents Chemother. 46, 3348-3355. doi: 10.1128/AAC.46.11.3348-3355.2002

Rodrigue, S., Provvedi, R., Jacques, P. E., Gaudreau, L., and Manganelli, R. (2006). The sigma factors of Mycobacterium tuberculosis. FEMS Microbiol. Rev. 30, 926-941. doi: 10.1111/j.1574-6976.2006.00040.x

Saini, V., Farhana, A., Glasgow, J. N., and Steyn, A. J. (2012a). Iron sulfur cluster proteins and microbial regulation: implications for understanding tuberculosis. Curr. Opin. Chem. Biol. 16, 45-53. doi: 10.1016/j.cbpa.2012.03.004

Saini, V., Raghuvanshi, S., Khurana, J. P., Ahmed, N., Hasnain, S. E., Tyagi, A. K., et al. (2012b). Massive gene acquisitions in Mycobacterium indicus pranii provide a perspective on mycobacterial evolution. Nucleic Acids Res. 40, 10832-10850. doi: 10.1093/nar/gks793

Salahudeen, A. A., Thompson, J. W., Ruiz, J. C., Ma, H. W., Kinch, L. N., Li, Q. et al. (2009). An E3 ligase possessing an iron-responsive hemerythrin domain is a regulator of iron homeostasis. Science 326, 722-726. doi: 10.1126/science. 1176326

Schaller, R. A., Ali, S. K., Klose, K. E., and Kurtz, D. M. Jr. (2012). A bacterial hemerythrin domain regulates the activity of a Vibrio cholerae diguanylate cyclase. Biochemistry 51, 8563-8570. doi: 10.1021/bi3011797

Schwede, T., Kopp, J., Guex, N., and Peitsch, M. C. (2003). SWISS-MODEL: an automated protein homology-modeling server. Nucleic Acids Res. 31, 3381-3385. doi: 10.1093/nar/gkg520 
Silva, M. S., Senna, S. G., Ribeiro, M. O., Valim, A. R., Telles, M. A., Kritski, A., et al. (2003). Mutations in katG, inhA, and ahpC genes of Brazilian isoniazid-resistant isolates of Mycobacterium tuberculosis. J. Clin. Microbiol. 41, 4471-4474. doi: 10.1128/JCM.41.9.4471-4474.2003

Singh, A. K., and Singh, B. N. (2008). Conservation of sigma F in mycobacteria and its expression in Mycobacterium smegmatis. Curr. Microbiol. 56, 574-580. doi: 10.1007/s00284-008-9126-8

Stover, C. K., De La Cruz, V. F., Fuerst, T. R., Burlein, J. E., Benson, L. A., Bennett, L. T., et al. (1991). New use of BCG for recombinant vaccines. Nature 351, 456-460. doi: 10.1038/351456a0

Trivedi, A., Singh, N., Bhat, S. A., Gupta, P., and Kumar, A. (2012). Redox biology of tuberculosis pathogenesis. Adv. Microb. Physiol. 60, 263-324. doi: 10.1016/B9780-12-398264-3.00004-8

Vashisht, A. A., Zumbrennen, K. B., Huang, X., Powers, D. N., Durazo, A., Sun, D., et al. (2009). Control of iron homeostasis by an ironregulated ubiquitin ligase. Science 326, 718-721. doi: 10.1126/science. 1176333

Vasudeva-Rao, H. M., and McDonough, K. A. (2008). Expression of the Mycobacterium tuberculosis acr-coregulated genes from the DevR (DosR) regulon is controlled by multiple levels of regulation. Infect. Immun. 76, 2478-2489. doi: 10.1128/IAI.01443-07

Wallace, R. J. Jr., Nash, D. R., Steele, L. C., and Steingrube, V. (1986). Susceptibility testing of slowly growing mycobacteria by a microdilution MIC method with 7H9 broth. J. Clin. Microbiol. 24, 976-981.

Wirstam, M., Lippard, S. J., and Friesner, R. A. (2003). Reversible dioxygen binding to hemerythrin. J. Am. Chem. Soc. 125, 3980-3987. doi: 10.1021/ja01 $7692 \mathrm{r}$
Wise, A. A., and Price, C. W. (1995). Four additional genes in the sigB operon of Bacillus subtilis that control activity of the general stress factor sigma B in response to environmental signals. J. Bacteriol. 177, 123-133.

Wu, H., Hu, X., Xiao, J., Zhang, J., Tao, J., Huang, H., et al. (2012). Sigma factor $F$ regulates Mycobacterium smegmatis hydrogen peroxide resistance. Wei Sheng Wu Xue Bao 52, 1352-1359.

Xiong, J., Kurtz, D. M. Jr., Ai, J., and Sanders-Loehr, J. (2000). A hemerythrin-like domain in a bacterial chemotaxis protein. Biochemistry 39, 5117-5125. doi: 10.1021/bi992796o

Conflict of Interest Statement: The authors declare that the research was conducted in the absence of any commercial or financial relationships that could be construed as a potential conflict of interest.

Received: 19 September 2014; accepted: 27 December 2014; published online: 15 January 2015.

Citation: Li X, Tao J, Hu X, Chan J, Xiao J and Mi K (2015) A bacterial hemerythrinlike protein $\mathrm{MsmHr}$ inhibits the SigF-dependent hydrogen peroxide response in mycobacteria. Front. Microbiol. 5:800. doi: 10.3389/fmicb.2014.00800

This article was submitted to Microbial Physiology and Metabolism, a section of the journal Frontiers in Microbiology.

Copyright (c) $2015 \mathrm{Li}$, Tao, Hu, Chan, Xiao and Mi. This is an open-access article distributed under the terms of the Creative Commons Attribution License (CC BY). The use, distribution or reproduction in other forums is permitted, provided the original author(s) or licensor are credited and that the original publication in this journal is cited, in accordance with accepted academic practice. No use, distribution or reproduction is permitted which does not comply with these terms. 